\title{
Study on the construction of Intelligent Courier Station Model
}

\author{
Ce zhao ${ }^{1, *}$, Jia xin $l u^{1}$, Zhuang zhuang $\mathrm{li}^{1}$, Zi rong shao ${ }^{1}$, Kun yi $\mathrm{pi}^{1}$ \\ ${ }^{1}$ Shan dong Jiao tong University, Ji nan, Shandong 250300, China
}

\begin{abstract}
Campus Express is an important window to observe the city consumption logistics service "last kilometer".The research on Campus Express service is not only conducive to campus environment improvement and service quality promotion, but also provides all types of community, agglomeration areas such as urban terminal "last kilometer" logistics with reference.This article first proposed the main problems of campus express service,analyzed the mode of smart express station and finally built a smart express station.
\end{abstract}

\section{Introduction}

In recent years, electronic commerce in China is developing rapidly, and the number of express business is increasing by more than $40 \%$ each year[1], which also causes great environmental pressure. In 2016, electronic commerce logistics used approximately 20,700 million express waybills, consumed about 9.922 billion crates, consumed about 3.1 billion woven bags, about 8.268 billion plastic bags, about 3.105 billion envelopes, and about 16.988 billion meters of tape.Electronic commerce packaging garbage in large and medium-sized cities accounts for $85 \%$ of the total amount of clean-up domestic waste[2], which has become the focus of attention of the whole society.In such environment, campus express delivery is rapidly developing with its unique market demand and living environment.However, the"last kilometer" distribution of campus express delivery has become a common problem for many colleges[3].

\section{The main problems of campus express service}

\subsection{Taking long time to take a piece}

At present, the rookie station uses self-raising express mode, customers need to find their own goods in the post, and then wait in line to scan code.Due to the unfamiliarity with the location of the goods and the relatively concentrated collection time of the students, the space was congested and chaotic, resulting in long time for picking up the parts and easy loss of goods.

\subsection{Frequent of truck in and out}

At present, the campus express is distributed from each express delivery company to the school's agents such as the Nojiri Station and the Neighboring Po.The large number of delivery vehicles and the inconsistent vehicle models have caused chaos in schools and increased the security risks and distribution costs on campus.

\subsection{A backlog of goods}

Due to the unreasonable layout of outlets, It is inconvenient for customers to pick up the parts, and it is easy to cause the backlog of goods.

\subsection{Low express packaging recycling}

Used courier boxes have not been properly recycled and are not easily reusable.

\section{Analysis on the mode of smart express station}

\subsection{Project plan}

\footnotetext{
* Corresponding author: $954190932 @$ qq.com
} 


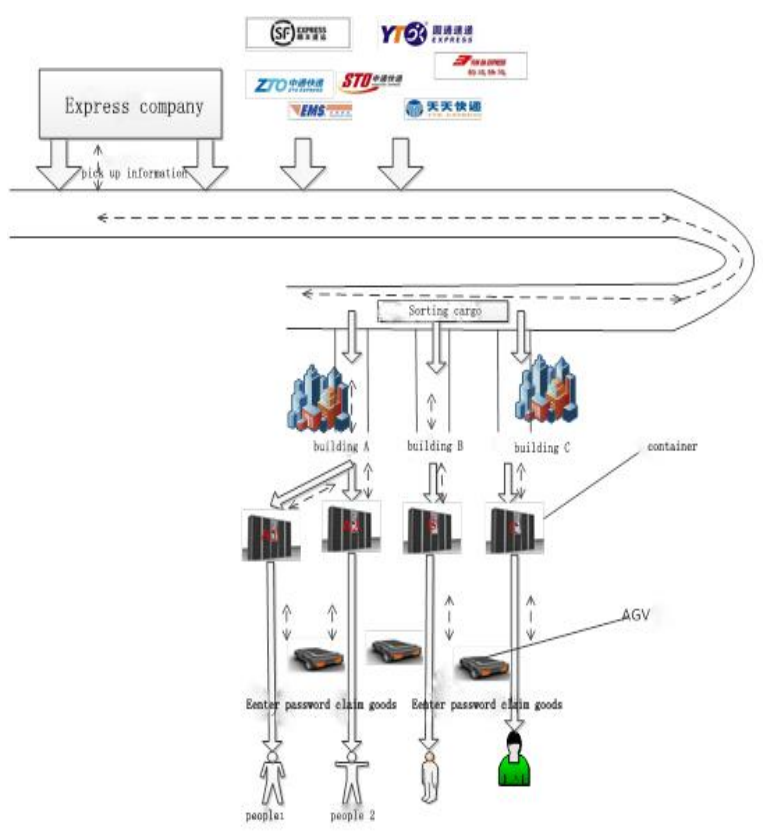

Fig. 1. Wisdom "e" Operation Mode

Integrate all the outlets in the school and establish a total distribution point in the school.In the smart express station, automatic sorting equipment is installed to automatically sort the goods. The goods will be sorted according to the building number information on the bar code to different shipping ports, and the loading personnel will carry out the loading according to the electronic tag-assisted picking system. The conveyor belts under the unit containers will dock the unit containers with AGV trolleys, and the AGV trolley will transport the unit containers to the designated location.Cell containers will be connected to the base.The AGV trolley transports empty cabinets or cabinets that have reached the set time to the recycling destination. The staff will inspect the lockers and classify and check the sent goods and the recovered cartons. The empty cabinet is circulated through the conveyor below to the sorting area.

Automating the distribution process and inspection process can improve efficiency and reduce manual labor. Staff concentrates on a single point to increase labor efficiency.Through the "shipping cabinet" mailing function, it is convenient for customers to send goods, through the recycling function, to increase the secondary use of recyclables.

\subsection{The Location of the Post Station and the Location of the Pick-up Outlets}

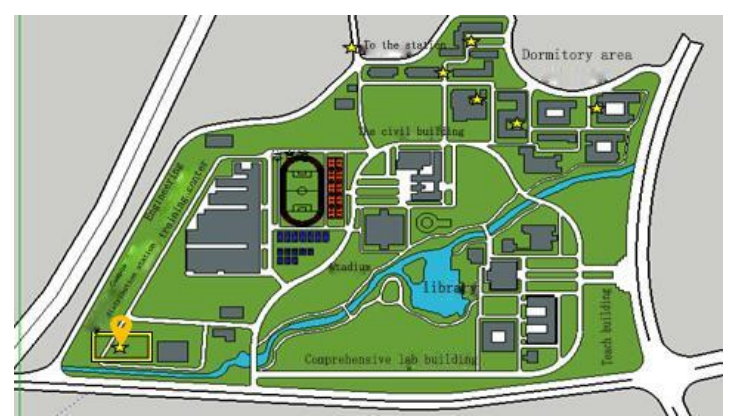

Fig. 2. Station Selection and Distribution Network
Note (the yellow box in the lower left corner is the new station set up, and the yellow part in the upper right corner is the location of the new self-introduction point)

Facilities and equipment layout have a close relationship with the optimization of express delivery services. The layout of facilities and equipment affects the optimization of express services.A good spatial layout is more conducive to the implementation of express delivery service optimization. The rational layout we have designed aims to achieve the following goals:The most efficient use of space; the most effective reduction in pick-up distances; the most efficient use of existing personnel.To achieve low-cost, high efficiency, high-quality express delivery.Through the investigation of the actual express transport volume on campus and the distribution of the actual number of people, we have selected the appropriate station locations and selfevaluation sites in accordance with the relevant regulations of the school. The smart express station is located at the south gate of the campus, away from the densely populated area of the campus to reduce potential safety hazards.Large area available in the area and can be placed into automatic sorting equipment.Close to the school gate, it is convenient for transportation of goods

\subsection{Route Selection}

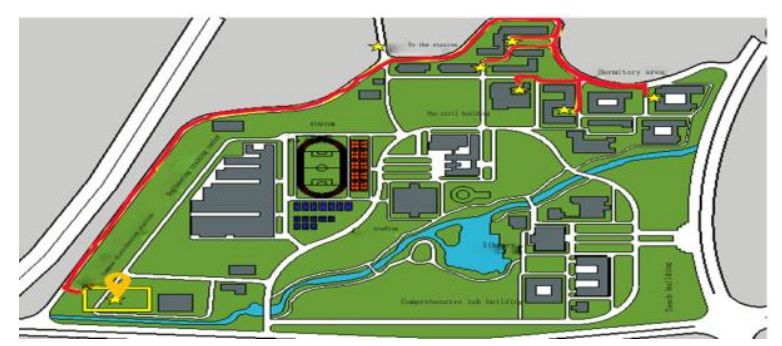

Fig. 3. Distribution Route Selection Place Campus Distribution route selection as shown in figure 3, figure in the red line is the $\mathrm{AGV}$ conductor. Route selection is edge route for the school, the number of students is less, it can not only ensure the safety of the goods, but also can reduce the traffic impact.

\section{The Construction of Intelligent Post Station}

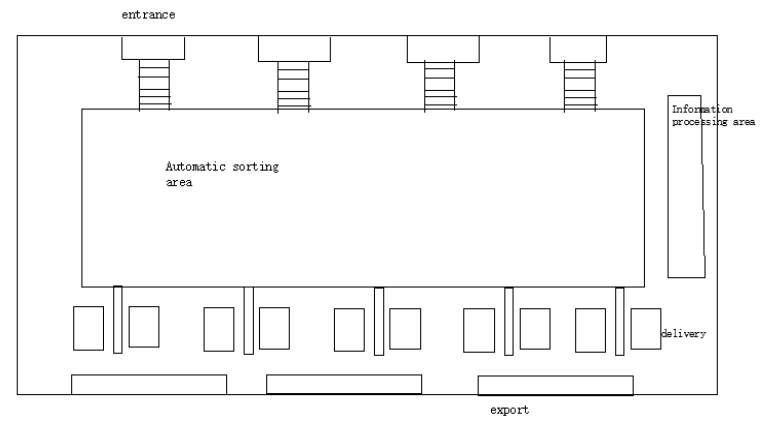

Fig.4.Post Space Layout

The post station space layout, as shown in Figure 4, it is based on the "smart campus green logistics platform" to build the campus smart station. The smart station is divided into four modules, it is include the collecting and 
sorting module, the delivery and recovery module, the distribution module and the information module. Using the automatic sorting system and its management platform, electronic label technology and RFID technology, it can improve the efficiency of the campus distribution service, promote the green recycling mode of innovative express packaging, develop the intelligent green logistics and create a new green new campus logistics model.

\subsection{Sorting Module}

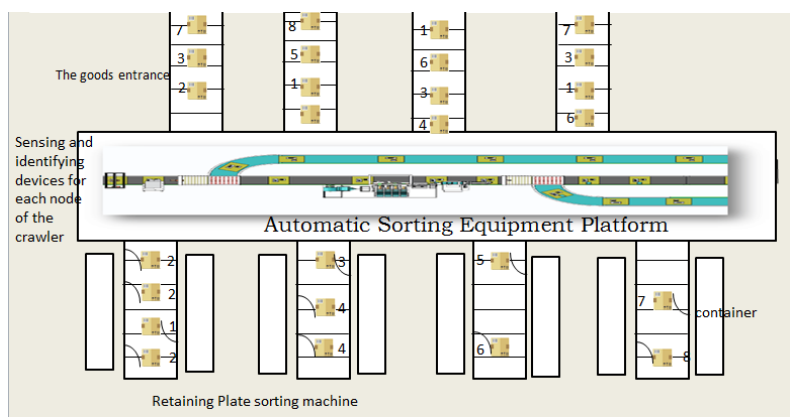

Fig. 5. the Sorting Facility Layout

The layout of the sorting facilities is shown in Figure 5. The goods are transported from the logistics company to the school, and the goods enter the sorting system through the track. After sorting, the goods enter the mobile unit express cabinet, and automatically connect with the AGV, it can achieve the aim that the power of unit, standardization, efficient and automated for service process.[5]. Using bar code identification technology to record and integrate information data and useing professional automatic sorting equipment to carry out automatic sorting processing for the aim we must to achieve according to user needs.Using automation facilities and resources advantages, the existing artificial processing mode is automated, efficient, and reduced manpower cost. The sorting process is shown in figure 6 :

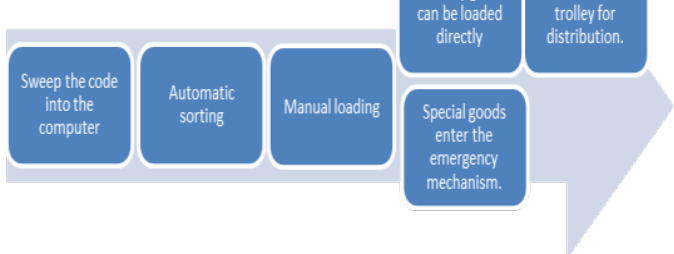

Fig. 6. Sorting Process

Goods will enter into the sorting system after ensure the information of the goods, and determine the size of goods according to the set of system data, then the belt sorting machine will classify the goods according to the number of floors, the goods will enter into the corresponding area according to corresponding number of address.For ordinary goods, they will be processed directly, and for special goods, such as fragile goods and so on will be handled through the emergency mechanism.

\subsection{Information Module}

Information management platform is the important guarantee of wisdom campus express operation mode, it will combine the relevant express information such as customer information, cargo information, then realize the uninterrupted seamless sharing and real-time monitoring and management of express information in all parts of the distribution line.

\subsection{Shipping and Recycling Module}

Delivery and recycling is an important part of the intelligent Courier Station, through the "ark" of the delivery and recovery function, convenient for customers to send goods, and more efficient recycling of resources. The staff check the cargo in the container, check and print and post the waybill, and return the deposit. For recycled cartons, the information management system will automatically set up the "environmental honor" file according to the information that the customer fills in. Then we will give customers reduce the cost of transportation .

\subsection{Distribution Module}

The entire distribution process is through the AGV and Information system operation completed, the entire distribution process to achieve a full automation and greatly reducing the loss of human factors.distribution flow as shown in Figure 7, the Unit container packing transport as shown in Figure8.

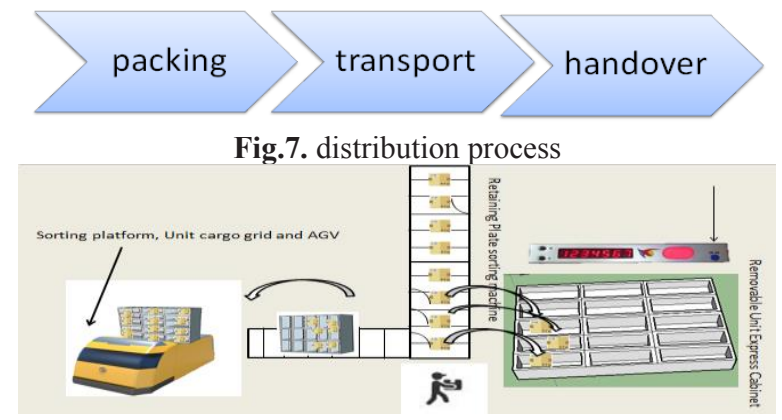

Fig. 8. transportation unit container packing

When the goods arrive at the sorting end, they are loaded by the staff according to the electronic tagassisted sorting system. The unit locker moves along the conveyor and completes the docking with the AGV car through the operation of the back-end information system. The AGV car travels along the preset line and arrives at the designated location, and then connects the interactive terminal with the express counter via RFID.The information management platform transmits the cargo information to the interactive terminal and sends a message to inform the customer of the arrival of the goods.For special goods, the staff will take the initiative to contact the customer or the customer can contact the staff through a fixed telephone, through the agreement agreed time and place, the staff will offer unified delivery or collection to special goods.

\section{Conclusion}

The project always adheres to the "green, safe, lowcarbon and high-efficiency" development concept.Based 
on the existing research results, we will continue to pay attention to the green logistics issues and "last kilometer" distribution issues that are urgently needed by the campus and the society, in-depth study of key technical equipment and application issues, and strive to build this project into teaching, research, and social service integration. The interactive demonstration project will guide the development of campus distribution to standardization, safety, and standardization.Through the demonstration and promotion of the project, the school will be built into a domestic campus logistics brand with influential characteristics.Afterwards, the project will be promoted and designed according to the specific conditions of other campuses. Eventually, all campus models will be integrated and the operation mode of large loops and small loops will be established.

\section{References}

1. Feng Xueyuan, Zhang Rujia, Gu Yuefang.Investigation and improvement suggestion on campus express logistics of comprehensive university [J].Hong Kong and Macao economy.2014 11: 63-64.

2. Lei Yun, Tu Qinghua, Song Junfei, Zhong Yuan.Construction and Research of efficient and Intelligent Campus Service platform in big data era [J].Communications World. 2017: 275-276.

3. Ding Yuanqing, Guo Xing, Wang Xiaotian, et al.Current situation and Development of Logistics recovery of waste goods in Colleges and Universities [J].Modern Commerce. 2017: 2: 188189.

4. Xi Peng. Analysis and improvement plan of university campus express mode [J].2017, (2): 104105

5. Yang Shiquan, Zhou Yanrong, Gu Shuhong.Research on the Distribution Mode of College Campus Express delivery in the era of Internet [J].Logistics Technology 2: 89-92 